\title{
Systemic therapy of psoriasis in diabetic patients
}

\author{
Paolo Gisondi*, Gabriele Perazzolli, Micol Del Giglio and Giampiero Girolomoni \\ Department of Medicine, Section of Dermatology, University of Verona, Italy
}

\begin{abstract}
Psoriasis is a chronic inflammatory skin disease affecting 2-3\% of worldwide population. Moderate to severe psoriasis is frequently associated with metabolic disorders including diabetes, obesity, dyslipidaemia, metabolic syndrome and non-alcoholic fatty liver disease. In particular, the prevalence of diabetes in patients with psoriasis ranges from 5 to $54 \%$. Most of the studies found that the prevalence of diabetes is higher in patients with moderate to severe psoriasis compared to mild disease. The association between psoriasis and diabetes could be explained considering several factors including a common genetic background, the high prevalence of metabolic risk factors for diabetes in patients with psoriasis as well as unhealthy life-styles such heavy drinking, over-eating and sedentary, which are common in patients with psoriasis. From a clinical prospective, the understanding of the patients in the context of metabolic comorbidities including diabetes is very important to ensure that treatment is tailored to meet the individual patient needs. Indeed, some pharmacological treatments may negatively affect metabolic comorbidities, and have important interactions with drugs that are commonly used to treat them. Non-pharmacological intervention such as diet and physical exercise could both improve the response to treatments for psoriasis and reduce the risk of diabetes and cardiovascular events.
\end{abstract}

\section{Introduction}

Psoriasis is a common chronic inflammatory disorder affecting approximately $2-3 \%$ of the general population, depending on ethnicity and geographical area [1]. It can occur at any age, although the majority of cases develop before the age of 50 years and it is uncommon in children. Psoriasis is considered to be an autoimmune disease, and the precise nature of the autoantigens triggering $\mathrm{T}$-cell responses is being elucidated [2]. Psoriasis has a strong genetic component with the majority of the patients having relatives affected [1]. The class I major histocompatibility complex (MHC) allele HLA-Cw6 is the strongest susceptibility factor for psoriasis. Other genetic predisposing factors include molecules involved in innate and adaptive immunity [3].

Chronic plaque psoriasis is the most common clinical variant of the disease [4] and the extent of skin involvement is widely variable, ranging from a few localized plaques at extensor sites to generalized involvement. Moderate to severe psoriasis is defined if the body surface involvement and/or the Dermatology life Quality Index is greater than 10. Patients with psoriasis, like those with other major medical disorders, have a decreased quality of life as well as a reduced employment and income [5]. Awareness is increasing that psoriasis is more than skin deep and that it is associated with comorbidities including metabolic disorders such as diabetes, obesity and metabolic syndrome.

\section{Chronic plaque psoriasis and diabetes, the epidemiological evidence}

The association of psoriasis with insulin-resistance and diabetes was firstly described more than 40 years ago [6]. More recently this association has been confirmed and further investigated in several epidemiological studies and meta-analysis. The prevalence of diabetes in patients with psoriasis ranges from 4.4 to $54 \%$ [7]. Most of the studies found that the prevalence of diabetes is higher in patients with moderate to severe psoriasis compared to mild disease [8] (Figure 1).

In a meta-analysis of 44 studies by Coto-Segura $\mathrm{P}$ et al. the pooled odds ratio for the association between psoriasis and diabetes was 1.76 (95\% CI 1.59-1.96). It was reported a "dose effect" in the risk of suffering from diabetes, as patients with severe psoriasis had higher risk compared with the pooled OR (OR 2.10, 95\% CI 1.73-2.55 versus OR 1.76, 95\% CI 1.59-1.96) [9]. The highest risk was for patients with psoriatic arthritis (OR 2.18, 95\% C.I.1.36-3.50) [9]. In another metaanalyses of observational studies $(n=27)$ psoriasis was associated also with an increased incidence of diabetes, other than prevalence. The study found that patients with psoriasis have a $27 \%$ increased risk of developing diabetes compared to the general population. In particular, those aged below 60 years and with more severe psoriasis carry the higher risk of developing diabetes [7]. Moreover, a Danish nationwide cohort study (study period 1997-2009) including 52.613 patients with psoriasis found that the incidence rate ratios of new-onset diabetes were increased in patients with psoriasis compared with the general population. Again, the incidence increased with psoriasis severity [10]. On the other hand, a case-control study by $\mathrm{Wu}$ et al. including 41.289 subjects, found that diabetic patients are at risk of developing psoriasis. The incidence rates of first-time psoriasis in diabetic patients and non-diabetic subjects were 70.2 cases and 42.5 cases per 100.000 person-years, respectively $(\mathrm{p}<0.001)$. The more severe the diabetes is, the higher the risk for psoriasis [11]. Furthermore, thiazolidinedione use has been associated with slightly lower risk of incident psoriasis (0.87, 95\% CI 0.77-0.99) [11].

A large cross-sectional survey (National Health and Nutrition Examination Survey) including 12.737 subjects reported an increased prevalence of obesity and hypertension among patients with psoriasis,

Correspondence to: Prof. Paolo Gisondi, Department of Medicine, Section of Dermatology, University of Verona. Piazzale A. Stefani , I-37126 Verona, Italy, Tel: +39-0458122547, Fax: +39-045-8027315; E-mail: paolo.gisondi@univr.it

Key words: psoriasis, diabetes, comorbidities, acitretin, cyclosporine, etanercept, adalimumab, infliximab, ustekinumab

Received: March 18, 2015; Accepted: April 28, 2015; Published: May 03, 2015 


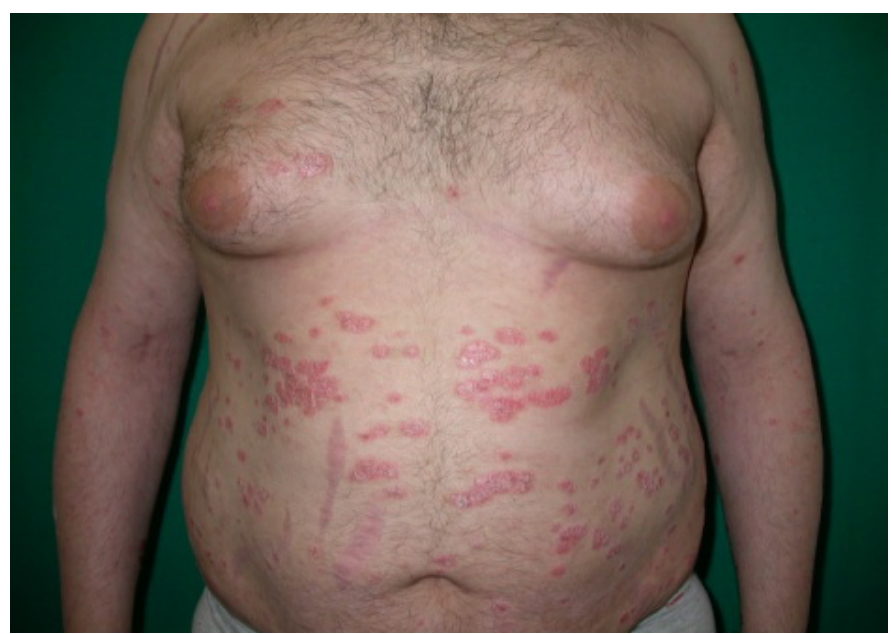

Figure 1. Plaques of psoriasis localised on the trunk of a overweighted patient with diabetes.

whereas it did not confirm an association with diabetes [12]. However, they included only five patients with severe psoriasis in their study.

Patients with moderate to severe psoriasis have an increased prevalence of the metabolic syndrome that is a cluster of metabolic disorders including abdominal obesity, impaired fasting glucose/ diabetes, dyslipidaemia and hypertension [13]. In a cross-sectional study, we found that patients with psoriasis had a higher prevalence of metabolic syndrome than those with other inflammatory skin diseases after adjusting for sex and age (30.1\% vs. $20.6 \%$, OR: 1.65 , 95\%C.I. 1.16 2.35) [14]. Non-alcoholic fatty liver disease (NAFLD) is recognized as the hepatic expression of the metabolic syndrome and these conditions have insulin resistance as a common pathophysiological mechanism [15]. We found that the prevalence of NAFLD in patients with chronic plaque psoriasis was greater than in controls $(47 \%$ vs. $28 \%$; $\mathrm{p}<0.0001)$ who were matched by age, sex and BMI [16]. Our findings have been also confirmed in a recent Dutch study. NAFLD was diagnosed in $46.2 \%$ of patients with psoriasis compared with $33.3 \%$ of the controls $(\mathrm{p}=0.005)$ [17]. Psoriasis was found associated to NAFLD independently of alcohol consumption, smoking status, presence of metabolic syndrome and serum levels of alanine aminotransferase (adjusted OR 1.7, 95\% CI 1.1-2.6) [17]. This is noteworthy as excess liver fat promotes hepatic insulin resistance, and NAFLD is recognized risk factor for diabetes $[18,19]$.

\section{Putative mechanisms of the association between psoriasis and diabetes}

The association between psoriasis and diabetes could be explained considering several factors including a common genetic background, the high prevalence of metabolic risk factors for diabetes in patients with psoriasis, the effects of chronic inflammation and insulin resistance as well as an unhealthy life-style such as heavy smoking/ drinking, over-eating habit and sedentary life, which are common in patients with psoriasis (Table 1).

It is likely that psoriasis and diabetes share common genetic background. Indeed, Suárez-Fariñas et al. [20] identified several genes biologically significant for psoriasis and metabolic disorders, including renin, cytotoxic T-lymphocyte antigen 4 (CTLA4) and Toll like receptor 3 (TLR3). Moreover, genetic variation at IL12B, IL23R and IL23A influences either the risk of psoriasis, its severity as well as type 2 diabetes mellitus [21]. Another study found that patients with psoriasis are enriched for certain common genetic variants (HLA, FUT2, UBE2L3, SH2B3) that predispose to dyslipidaemia, hypertension and cardiovascular risk [22]. The presence of risk factors for diabetes in patients with psoriasis is quite common. Patients with psoriasis are more frequently overweight or obese than the general population, and the severity of psoriasis is correlated to body mass index (BMI) $[23,24]$. Obesity generally precedes the development of psoriasis and the BMI is correlated to an increased risk of incident psoriasis [25]. Several measures of adiposity, including BMI, waist and hip circumference and waist-hip ratio have been reported as independent risk factors for the development of psoriasis and psoriatic arthritis (PsA) [25]. The relationships between psoriasis and obesity are largely explained by the complex properties of the adipose tissue. Indeed, the adipose tissue is not only a storage fat organ but also an active endocrine organ with many other secretory products, such as free fatty acids, adipocytederived hormones and pro-inflammatory adipokines including chemerin, leptin and adiponectin, which are released by macrophages and lymphocytes [26]. Increased chemerin and leptin and reduced adiponectin serum have been reported in patients with psoriasis compared to age, sex and BMI matched controls. [27-29]. Obesity is a strong risk factor for insulin resistance and diabetes [30]. Moreover, psoriatic keratinocytes release pro-inflammatory cytokines including IL- $1 \beta$ that induce insulin resistance and may favour the development of diabetes [26,31]. Indeed, IL- $1 \beta$ is present in high quantities in the tissue fluid collected via micro-dialysis from patients with psoriasis and its levels are reduced under successful anti-psoriatic therapy. IL$1 \beta$ contributes to diabetes and psoriasis by inducing insulin resistance through p38MAPK (mitogen activated protein kinase), which blocks insulin-dependent differentiation of keratinocytes and drives their proliferation [32]. Buerger et al. showed that long-term IL-1 $\beta$ treatment induces insulin resistance in metabolically active tissues. At the same time, IL- $1 \beta$ is able to activate protein kinase $\mathrm{B}(\mathrm{PKB})$ via a different set of kinases such as c-Jun N-terminal kinase (JNK) or p38MAPK, which results in induction of cell proliferation. They assume that PKB preferentially induces proliferative pathways, whereas the insulindependent and differentiation-inducing functions are shut off by means of insulin resistance $[32,33]$.

The hypothesis that psoriasis itself constitutes a pre-diabetic condition has been suggested by the study of Gyldenløve et al. conducted over 32 patients with psoriasis [34]. They found that normal glucose-tolerant psoriatic patients had reduced insulin sensitivity. In this study the gold standard hyperinsulinemic-euglycemic clamp technique was used and psoriatic patients exhibited reduced insulin sensitivity compared with controls. Furthermore, C-peptide and glucagon levels during the hyperinsulinemic-euglycemic clamp tended to be higher in the psoriasis group.

On the other hand, it is also possible that the coexisting metabolic comorbidities might directly contribute to exacerbate psoriatic inflammation through the release of several pro-inflammatory mediators from the liver and/or visceral adipose tissues, such as

Table 1. Putative mechanisms of the association between psoriasis and type 2 diabetes mellitus.

Common genetic background

High prevalence of risk factors for diabetes in patients with psoriasis (i.e. obesity, insulin resistance)

Common inflammatory pathways (i.e. TNF-alpha, IL-1 beta)

Unhealthy life-styles (heavy drinking, over-eating and sedentary) 
increased reactive oxygen species, $\mathrm{C}$ reactive protein (CRP), IL- 6 and other adipokines [29]. Further research is needed to investigate the complex relationship between psoriasis and diabetes at both clinical and molecular level.

\section{Management of patients with moderate to severe psoriasis and diabetes}

The association between psoriasis and cardio-metabolic disorders has important clinical implications [35]. In particular, methotrexate [MTX] should be administered with caution for long-term course in the presence of obesity, type 2 diabetes, NAFLD and heavy alcohol intake because of the increased risk of liver fibrosis [36]. In addition, it should be considered that chronic kidney disease that is common in older patients and in patients with diabetes could reduce renal clearance of MTX favouring toxicity [37]. Besides, treatment with MTX is not associated with a reduction in diabetes risk [38] or change in usual anti-diabetic therapy [39]. MTX associated with TNF inhibitors does not affect fasting plasma glucose and $\mathrm{Hb}-\mathrm{A} 1 \mathrm{C}$ when compared to MTX alone [40].

Cyclosporine can induce or worsen arterial hypertension, interfere with fatty acid metabolism inducing dyslipidaemia and hyperuricaemia [41]. Cyclosporine treatment is significantly associated with the risk of developing diabetes [41]. Then, the drug interaction between cyclosporine and statins, which are commonly used for hypercholesterolemia, could potentially induce rabdomiolysis [42]. Consequently, cyclosporine should be used with caution in psoriatic patients with metabolic syndrome. Moreover, the presence of an established renal disease is a contraindication for cyclosporine.

Acitretin is a vitamin A derivative that has been used to treat psoriasis since the early 1980s. Acitretin therapy is associated with increased risk of hypertriglyceridemia and/or hypercholesterolemia [41]. There is a very limited evidence supporting that acitretin may decrease insulin resistance (IR), Homeostasis Model Assessment IR (HOMA-IR) and adipokines production [43].

PUVA and narrowband UVB therapy are not expected to cause significant changes in metabolic parameters [44], including glycaemia.

TNF-alpha antagonists have represented an important advancement in the therapy of psoriasis as well as many others TNFrelated conditions, their use being associated with generally rapid improvement of clinical manifestation. As previously mentioned systemic inflammation link psoriasis to type 2 diabetes mellitus, and in this contest biological therapy with TNF-alpha agents would be expected to show beneficial effects on psoriasis comorbidities. Generally, biological therapies do not negatively affect metabolic parameters as conventional treatments can do. Indeed, Solomon DH et al. found that patients with rheumatoid arthritis or psoriasis receiving TNF-inhibitors have lower risk of developing diabetes compared with other disease modifying anti-rheumatic drug [38]. The Author speculated this effect being related to the inhibition of TNF-alpha capable of altering insulin sensitivity $[38,45]$. Clinically meaningful dyslipidaemia has been rarely reported in patients receiving TNF-alpha antagonists. [46].

A body weight gain could occur in patients treated with TNF- $\alpha$ antagonists $[47,48]$. Weight changes are induced mainly by fat mass gain in patients with psoriasis receiving TNF-alpha antagonists [47]. Ustekinumab is not associated with weight gain in patients with chronic plaque psoriasis [49]. The effects of TNF- $\alpha$ inhibitors therapy on insulin sensitivity are controversial [50,51]. The effects of anti-TNFs on glycaemic parameters and insulin resistance in patients with psoriasis have been addressed mostly in small studies by means of the HOMA and the Quantitative Insulin Sensitivity Check Index (QUICKI], two widely used non-invasive surrogate markers of insulin resistance and sensitivity, respectively. Several studies evaluating the effects of infliximab on insulin resistance and sensitivity have revealed a decrease in resistance and an increase in sensitivity. It is noteworthy that infliximab treatment may have beneficial effects on insulin sensitivity [52,53]. A randomized, double-blind study in 12 psoriatic patients at high risk of developing type 2 diabetes mellitus failed to see a significant effect of a 2-week treatment with etanercept on insulin secretion and sensitivity [54]. In contrast, a 24-week study in 9 patients with stable active plaque psoriasis treated with etanercept found a significant reduction in insulin plasma levels, with a significant improvement in insulin resistance as suggested by the decrease in the HOMA index [55]. In accordance with that, another study in 40 obese subjects with metabolic syndrome suggested that treatment with etanercept improves insulin sensitivity [56]. In addition, there have been isolated reports of diabetic patients with psoriasis or rheumatoid arthritis who developed unpredictable hypoglycaemia during treatment with etanercept $[57,58]$. There have been no studies investigating the effects of adalimumab on insulin resistance in psoriatic patients. Only one case report describe a patient with psoriasis, psoriatic spondyloarthritis and type 2 diabetes who developed recurrent hyperglycaemia during adalimumab treatment [59]; when the patient switched to etanercept no hyperglycaemic episodes were noted. Moreover, no significant changes in insulin sensitivity or in the levels of fasting blood glucose were seen in 9 patients with psoriasis after 12 weeks of treatment with adalimumab [60].

Ustekinumab has proven to be highly effective in psoriasis, but its effect on insulin resistance has not been investigated. Long-term use of topical corticosteroids may be associated with significant systemic absorption interfering with insulin sensitivity and optimal control of diabetes [61].

Finally, patients with moderate-to-severe psoriasis are candidate to interventions aimed to reduce their cardiovascular risk including hypo-caloric diet, regular physical activity and smoking cessation. Low calorie diet inducing a moderate weight loss (i.e. 5 to $10 \%$ of body weight) increases the responsiveness of obese patients to any systemic treatments [62-64]. Smoking habit has been associated to onset and worsening of psoriasis, and smoking cessation can positively affect the disease course [65]. Patients with psoriasis exhibit a decreased level of physical activity, possibly for both psychological and physiological reasons [66]. Regular physical activity may lower the risk of incident psoriasis and have also a beneficial effect on the natural course of the disease influencing the response to therapy as well as metabolic comorbidities [62,67].

\section{Concluding remarks}

From a clinical prospective, the understanding of patients with moderate-to-severe psoriasis in the context of metabolic comorbidities is very important to ensure that treatment is tailored to meet the specific individual patient needs. Appropriate patient monitoring and counselling, and therapy selection are important to maximize metabolic safety. In particular, it is important that patients with psoriasis are screened and monitored for diabetes. Studies addressing the effects of systemic treatments on glucose homeostasis in patients with psoriasis were very limited, making it not reasonable to give any formal 
recommendations on the most appropriate treatment. However, we may suggest not using cyclosporine as a first line treatment in patients with diabetes since it may reduce insulin sensitivity. In contrast, preliminary evidence suggests that TNF- $\alpha$ inhibitors may be beneficial on insulin resistance on long term. Methotrexate does not affect insulin resistance. Finally, non-pharmacological interventions including hypocaloric diet, regular physical activity and smoking cessation could be recommended in psoriasis patients with metabolic disorders including obesity and diabetes

\section{Conflict of interest disclosure}

- Paolo Gisondi has been a consultant and/or speaker for Abbott, Celgene, Janssen, Leo-pharma, Lilly, Merck Sharp and Dohme, Novartis and Pfizer.

\section{- Gabriele Perazzolli has nothing to declare.}

- Micol Del Giglio has been a consultant/investigator for Abbott, Janssen, Novartis and Pfizer.

Giampiero Girolomoni has been principal investigator and/or received personal fee from AbbVie, Almirall, Amgen, BoeringherIngelheim, Celgene, Dompè, Galderma, GlaxoSmithKline, Eli-Lilly, Hospira, Janssen, Leo Pharma, Merck Serono, Merck Sharp \&Dohme, Mundipharma, Novartis, Otsuka, Pfizer and Shiseido.

\section{References}

1. Christophers E (2001) Psoriasis--epidemiology and clinical spectrum. Clin Exp Dermatol 26: 314-320. [Crossref]

2. Lande R, Botti E, Jandus C, Dojcinovic D, Fanelli G, et al. (2014) The antimicrobial peptide LL37 is a T-cell autoantigen in psoriasis. Nat Commun 5: 5621. [Crossref]

3. Chandran V, Raychaudhuri SP (2010) Geoepidemiology and environmental factors of psoriasis and psoriatic arthritis. J Autoimmun 34: J314-321. [Crossref]

4. Nestle FO, Kaplan DH, Barker J (2009) Psoriasis. N Engl J Med 361: 496-509. [Crossref]

5. Gisondi P, Girolomoni G (2013) Impact of TNF- $\alpha$ antagonists on the quality of life in selected skin diseases. G Ital Dermatol Venereol 148: 243-248. [Crossref]

6. Binazzi M, Calandra P, Lisi P (1975) Statistical association between psoriasis and diabetes: further results. Arch Dermatol Res 254: 43-48. [Crossref]

7. Armstrong AW, Harskamp CT, Armstrong EJ (2013) Psoriasis and the risk of diabetes mellitus: a systematic review and meta-analysis. JAMA Dermatol 149: 84-91. [Crossref]

8. Al-Mutairi N, Al-Farag S, Al-Mutairi A, Al-Shiltawy M (2010) Comorbidities associated with psoriasis: an experience from the Middle East. $J$ Dermatol 37: 146155. [Crossref]

9. Coto-Segura P, Eiris-Salvado N, González-Lara L, Queiro-Silva R, Martinez-Camblor P, et al. (2013) Psoriasis, psoriatic arthritis and type 2 diabetes mellitus: a systematic review and meta-analysis. Br J Dermatol 169: 783-793. [Crossref]

10. Khalid U, Hansen PR, Gislason GH, Lindhardsen J, Kristensen SL, et al. (2013) Psoriasis and new-onset diabetes: a Danish nationwide cohort study. Diabetes Care 36: 2402-2407. [Crossref]

11. Wu CY, Shieh JJ, Shen JL, Liu YY, Chang YT, et al. (2015) Association between antidiabetic drugs and psoriasis risk in diabetic patients: results from a nationwide nested case-control study in Taiwan. J Am Acad Dermatol 72: 123-130. [Crossref]

12. Casagrande SS, Menke A, Cowie CC (2014) No association between psoriasis and diabetes in the U.S. population. Diabetes Res Clin Pract 104: e58-60. [Crossref]

13. Sommer DM, Jenisch S, Suchan M, Christophers E, Weichenthal M (2006) Increased prevalence of the metabolic syndrome in patients with moderate to severe psoriasis. Arch Dermatol Res 298: 321-328. [Crossref]

14. Gisondi P, Tessari G, Conti A, Piaserico S, Schianchi S, et al. (2007) Prevalence of metabolic syndrome in patients with psoriasis: a hospital-based case-control study. $\mathrm{Br}$ J Dermatol 157: 68-73. [Crossref]

15. Targher G, Byrne CD (2013) Clinical Review: Nonalcoholic fatty liver disease: a novel cardiometabolic risk factor for type 2 diabetes and its complications. J Clin Endocrinol Metab 98: 483-495. [Crossref]

16. Gisondi P, Targher G, Zoppini G, Girolomoni G (2009) Non-alcoholic fatty liver disease in patients with chronic plaque psoriasis. J Hepatol 51: 758-764. [Crossref]

17. van der Voort EA, Koehler EM, Dowlatshahi EA, Hofman A, Stricker BH, et al. (2014) Psoriasis is independently associated with nonalcoholic fatty liver disease in patients 55 years old or older: Results from a population-based study. J Am Acad Dermatol 70: 517-524. [Crossref]

18. Prey S, Paul C, Bronsard V, Puzenat E, Gourraud PA, et al. (2010) Cardiovascular risk factors in patients with plaque psoriasis: a systematic review of epidemiological studies. J Eur Acad Dermatol Venereol JEADV 24: 23-30. [Crossref]

19. Samarasekera EJ, Neilson JM, Warren RB, Parnham J, Smith CH (2013) Incidence of cardiovascular disease in individuals with psoriasis: a systematic review and metaanalysis. J Invest Dermatol 133: 2340-2346. [Crossref]

20. Suárez-Fariñas M, Li K, Fuentes-Duculan J, Hayden K, Brodmerkel C, et al. (2012) Expanding the psoriasis disease profile: interrogation of the skin and serum of patients with moderate-to-severe psoriasis. J Invest Dermatol 132: 2552-2564. [Crossref]

21. Eirís N, González-Lara L, Santos-Juanes J, Queiro R, Coto E, et al. (2014) Genetic variation at IL12B, IL23R and IL23A is associated with psoriasis severity, psoriatic arthritis and type 2 diabetes mellitus. J Dermatol Sci 75: 167-172. [Crossref]

22. Henseler T, Christophers E (1995) Disease concomitance in psoriasis. J Am Acad Dermatol 32: 982-986. [Crossref]

23. Armstrong AW, Harskamp CT, Armstrong EJ (2012) The association between psoriasis and obesity: a systematic review and meta-analysis of observational studies. Nutr Diabetes 2: e54. [Crossref]

24. Setty AR, Curhan G, Choi HK (2007) Obesity, waist circumference, weight change, and the risk of psoriasis in women: Nurses' Health Study II. Arch Intern Med 167: 1670-1675. [Crossref]

25. Soltani-Arabshahi R, Wong B, Feng BJ, Goldgar DE, Duffin KC, et al. (2010) Obesity in early adulthood as a risk factor for psoriatic arthritis. Arch Dermatol 146: 721-726. [Crossref]

26. Davidovici BB, Sattar N, Prinz J, Puig L, Emery P, et al. (2010) Psoriasis and systemic inflammatory diseases: potential mechanistic links between skin disease and co-morbid conditions. J Invest Dermatol 130: 1785-1796. [Crossref]

27. Shibata S, Saeki H, Tada Y, Karakawa M, Komine M, et al. (2009) Serum high molecular weight adiponectin levels are decreased in psoriasis patients. J Dermatol Sci 55: 62-63. [Crossref]

28. Takahashi H, Tsuji H, Takahashi I, Hashimoto Y, Ishida-Yamamoto A, et al. (2008) Plasma adiponectin and leptin levels in Japanese patients with psoriasis. Br J Dermatol 159: 1207-1208. [Crossref]

29. Gisondi P, Lora V, Bonauguri C, Russo A, Lippi G, et al. (2013) Serum chemerin is increased in patients with chronic plaque psoriasis and normalizes following treatment with infliximab. Br J Dermatol 168: 749-755. [Crossref]

30. Bonadonna RC, Groop L, Kraemer N, Ferrannini E, Del Prato S, et al. (1990) Obesity and insulin resistance in humans: a dose-response study. Metabolism 39: 452-459. [Crossref]

31. Groves RW, Rauschmayr T, Nakamura K, Sarkar S, Williams IR, et al. (1996) Inflammatory and hyperproliferative skin disease in mice that express elevated levels of the IL-1 receptor (type I) on epidermal keratinocytes. Evidence that IL-1-inducible secondary cytokines produced by keratinocytes in vivo can cause skin disease. $J$ Clin Invest 98: 336-344. [Crossref]

32. Buerger C, Richter B, Woth K, Salgo R, Malisiewicz B, et al. (2012) Interleukin$1 \beta$ interferes with epidermal homeostasis through induction of insulin resistance implications for psoriasis pathogenesis. J Invest Dermatol 132: 2206-2214. [Crossref]

33. He J, Usui I, Ishizuka K, Kanatani Y, Hiratani K, et al. (2006) Interleukin-1 $\alpha$ inhibits insulin signaling with phosphorylating insulin receptor substrate-1 on serine residues in 3T3-L1 adipocytes. Mol Endocrinol Baltim Md 20: 114-124. [Crossref]

34. Gyldenløve M, Storgaard H, Holst JJ, Vilsbøll T, Knop FK, et al. (2015) Patients with psoriasis are insulin resistant. J Am Acad Dermatol 72: 599-605. [Crossref]

35. Yazdani-Biuki B, Stelzl H, Brezinschek HP, Hermann J, Mueller T, et al. (2004) Improvement of insulin sensitivity in insulin resistant subjects during prolonged treatment with the anti-TNF- $\alpha$ antibody infliximab. Eur $J$ Clin Invest 34: 641-642. [Crossref]

36. Rosenberg P, Urwitz H, Johannesson A, Ros AM, Lindholm J, et al. (2007) Psoriasis 
patients with diabetes type 2 are at high risk of developing liver fibrosis during methotrexate treatment. J Hepatol 46: 1111-1118. [Crossref]

37. Balato N, Patruno C, Napolitano M, Patrì A, Ayala F, et al. (2014) Managing moderateto-severe psoriasis in the elderly. Drugs Aging 31: 233-238. [Crossref]

38. Solomon DH, Massarotti E, Garg R, Liu J, Canning C, et al. (2011) Association between disease-modifying antirheumatic drugs and diabetes risk in patients with rheumatoid arthritis and psoriasis. JAMA 305: 2525-2531. [Crossref]

39. Wu JJ, Liu L, Asgari MM, Curtis JR, Harrold L, et al. (2014) Initiation of TNF inhibitor therapy and change in physiologic measures in psoriasis. J Eur Acad Dermatol Venereol 28: 1380-1387. [Crossref]

40. Wu JJ, Rowan CG, Bebchuk JD, Anthony MS (2015) No Association Between TNF Inhibitor and Methotrexate Therapy Versus Methotrexate in Changes in Hemoglobin A1C and Fasting Glucose Among Psoriasis, Psoriatic Arthritis, and Rheumatoid Arthritis Patients. J Drugs Dermatol JDD 14: 159-166. [Crossref]

41. Gisondi P, Cazzaniga S, Chimenti S, Giannetti A, Maccarone M, et al. (2013) Metabolic abnormalities associated with initiation of systemic treatment for psoriasis: evidence from the Italian Psocare Registry. J Eur Acad Dermatol Venereol 27: e30-41. [Crossref]

42. Neuvonen PJ, Niemi M, Backman JT (2006) Drug interactions with lipid-lowering drugs: mechanisms and clinical relevance. Clin Pharmacol Ther 80: 565-581. [Crossref]

43. Karadag AS, Ertugrul DT, Kalkan G, Bilgili SG, Celik HT, et al. (2013) The effect of acitretin treatment on insulin resistance, retinol-binding protein-4, leptin, and adiponectin in psoriasis vulgaris: a noncontrolled study. Dermatol Basel Switz 227: 103-108. [Crossref]

44. Chappe SG, Roenigk HH Jr, Miller AJ, Beeaff DE, Tyrpin L (1981) The effect of photochemotherapy on the cardiovascular system. J Am Acad Dermatol 4: 561-566. [Crossref]

45. Liu S, Tinker L, Song Y, Rifai N, Bonds DE, et al. (2007) A prospective study of inflammatory cytokines and diabetes mellitus in a multiethnic cohort of postmenopausal women. Arch Intern Med 167: 1676-1685. [Crossref]

46. Lestre S, Diamantino F, Veloso L, Fidalgo A, Ferreira A (2011) Effects of etanercept treatment on lipid profile in patients with moderate-to-severe chronic plaque psoriasis: a retrospective cohort study. Eur J Dermatol 21: 916-920. [Crossref]

47. Renzo LD, Saraceno R, Schipani C, Rizzo M, Bianchi A, et al. (2011) Prospective assessment of body weight and body composition changes in patients with psoriasis receiving anti-TNF- $\alpha$ treatment. Dermatol Ther 24: 446-451. [Crossref]

48. Gisondi P, Cotena C, Tessari G, Girolomoni G (2008) Anti-tumour necrosis factoralpha therapy increases body weight in patients with chronic plaque psoriasis: a retrospective cohort study. J Eur Acad Dermatol Venereol 22: 341-344. [Crossref]

49. Gisondi P, Conti A, Galdo G, Piaserico S, De Simone C, et al. (2013) Ustekinumab does not increase body mass index in patients with chronic plaque psoriasis: a prospective cohort study. Br J Dermatol 168: 1124-1127. [Crossref]

50. Stagakis I, Bertsias G, Karvounaris S, Kavousanaki M, Virla D, et al. (2012) Antitumor necrosis factor therapy improves insulin resistance, beta cell function and insulin signaling in active rheumatoid arthritis patients with high insulin resistance. Arthritis Res Ther 14: R141. [Crossref]

51. Campanati A, Ganzetti G, Di Sario A, Damiani A, Sandroni L, et al. (2013) The effect of etanercept on hepatic fibrosis risk in patients with non-alcoholic fatty liver disease, metabolic syndrome, and psoriasis. J Gastroenterol 48: 839-846. [Crossref]
52. Gonzalez-Gay MA, De Matias JM, Gonzalez-Juanatey C, Garcia-Porrua C, SanchezAndrade A, et al. (2006) Anti-tumor necrosis factor-alpha blockade improves insulin resistance in patients with rheumatoid arthritis. Clin Exp Rheumatol 24: 83-86. [Crossref]

53. Huvers FC, Popa C, Netea MG, van den Hoogen FH, Tack CJ (2007) Improved insulin sensitivity by anti-TNFalpha antibody treatment in patients with rheumatic diseases. Ann Rheum Dis 66: 558-559. [Crossref]

54. Martínez-Abundis E, Reynoso-von Drateln C, Hernández-Salazar E, González-Ortiz M (2007) Effect of etanercept on insulin secretion and insulin sensitivity in a randomized trial with psoriatic patients at risk for developing type 2 diabetes mellitus. Arch Dermatol Res 299: 461-465. [Crossref]

55. Marra M, Campanati A, Testa R, Sirolla C, Bonfigli AR, et al. (2007) Effect of etanercept on insulin sensitivity in nine patients with psoriasis. Int J Immunopathol Pharmacol 20: 731-736. [Crossref]

56. Stanley TL, Zanni MV, Johnsen S, Rasheed S, Makimura H, et al. (2011) TNFantagonism with etanercept decreases glucose and increases the proportion of high molecular weight adiponectin in obese subjects with features of the metabolic syndrome. J Clin Endocrinol Metab 96: E146-150. [Crossref]

57. Boulton JG, Bourne JT (2007) Unstable diabetes in a patient receiving anti-TNF- $\alpha$ for rheumatoid arthritis. Rheumatology (Oxford) 46: 178-179. [Crossref]

58. Bonilla E, Lee YY, Phillips PE, Perl A (2007) Hypoglycaemia after initiation of treatment with etanercept in a patient with type 2 diabetes mellitus. Ann Rheum Dis 66: 1688. [Crossref]

59. Wu JJ, Tsai TF (2008) Recurrent hyperglycemia during adalimumab treatment in a patient with psoriasis. Arch Dermatol 144: 1403-1404. [Crossref]

60. Kofoed K, Clemmensen A, Mikkelsen UR, Simonsen L, Andersen O, et al. (2012) Effects of anti-tumor necrosis factor therapy on body composition and insulin sensitivity in patients with psoriasis. Arch Dermatol 148: 1089-1091. [Crossref]

61. Gottschalk J, Einspanier A, Ungemach FR, Abraham G (2011) Influence of topica dexamethasone applications on insulin, glucose, thyroid hormone and cortisol levels in dogs. Res Vet Sci 90: 491-497. [Crossref]

62. Gisondi P, Del Giglio M, Di Francesco V, Zamboni M, Girolomoni G (2008) Weight loss improves the response of obese patients with moderate-to-severe chronic plaque psoriasis to low-dose cyclosporine therapy: a randomized, controlled, investigatorblinded clinical trial. Am J Clin Nutr 88: 1242-1247. [Crossref]

63. Naldi L, Conti A, Cazzaniga S, Patrizi A, Pazzaglia M, et al. (2014) Diet and physica exercise in psoriasis: a randomized controlled trial. $\mathrm{Br} J$ Dermatol 170: 634-642. [Crossref]

64. Jensen P, Zachariae C, Christensen R, Geiker NR, Schaadt BK, et al. (2013) Effect of weight loss on the severity of psoriasis: a randomized clinical study. JAMA Dermatol 149: 795-801. [Crossref]

65. Kinahan CE, Mazloom S, Fernandez AP (2015) Impact of smoking on response to systemic treatment in patients with psoriasis: a retrospective case-control study. $\mathrm{Br} J$ Dermatol 172: 428-436. [Crossref]

66. Torres T, Alexandre JM, Mendonça D, Vasconcelos C, Silva BM, et al. (2014) Level of physical activity in patients with severe psoriasis: a cross-sectional questionnaire study. Am J Clin Dermatol 15: 129-135. [Crossref]

67. Balato N, Megna M, Palmisano F, Patruno C, Napolitano M, et al. (2015) Psoriasis and sport: a new ally? J Eur Acad Dermatol Venereol 29: 515-520. [Crossref]

Copyright: $\odot 2015$ Gisondi P. This is an open-access article distributed under the terms of the Creative Commons Attribution License, which permits unrestricted use, distribution, and reproduction in any medium, provided the original author and source are credited. 